\title{
Cuidado e reconstrução das práticas de Saúde*
}
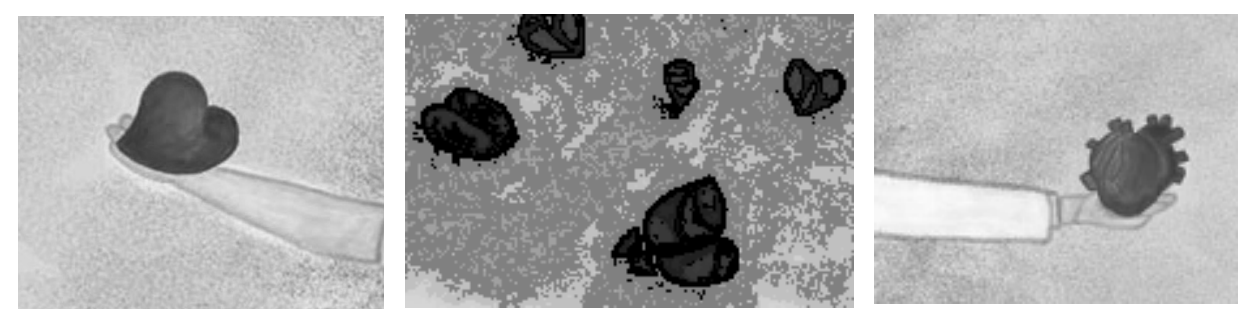

José Ricardo de Carvalho Mesquita Ayres ${ }^{1}$

AYRES, J. R. C. M. Care and reconstruction in healthcare practices, Interface - Comunic., Saúde, Educ., v.8, n.14, p.73-92, set.2003-fev.2004.

In recent years, we have witnessed the appearance of a series of new lines of discourse in the field of public health, both globally and domestically, such as health promotion, health vigilance, family health and vulnerability reduction, among others. However, it seems to us that a true consolidation of these proposals and their consequent development depends on fairly radical transformation of our way of thinking about and providing healthcare, especially with regard to its assumptions and its underlying philosophical principles. We would like to bring these thoughts to the debate as a theoretical deconstruction, with a view to contributing to the reconstruction that is underway in healthcare practices. Thus, care is examined from three conceptual points of view: as an ontological category, as a genealogical category and as a critical category. Hermeneutics applied to the interface of these three points of view allows one to indicate directions that may yield a productive effort of healthcare practice reconstruction: an active movement of the professionals and healthcare services toward actively acknowledging the presence of another party in the arena of care, the optimization and diversification of the forms and quality of the "I-Other" interaction in this arena and the enrichment of the horizons of healthcare knowledge and performance from a decidedly interdisciplinary and intersectorial perspective.

KEY WORDS: Health promotion; public health practice.

Assistimos em tempos recentes à emergência de uma série de novos discursos no campo da saúde pública, mundial e nacionalmente, tais como a promoção da saúde, vigilância da saúde, saúde da família, redução de vulnerabilidade, entre outros. Contudo, uma efetiva consolidação dessas propostas e seu mais conseqüente desenvolvimento parece-nos depender de transformações bastante radiçais no nosso modo de pensar e fazer saúde, especialmente em seus pressupostos e fundamentos filosóficos. É na condição de uma desconstrução teórica, com vistas a contribuir para a reconstrução em curso nas práticas de saúde, que se quer trazer ao debate a presente reflexão. Nesse sentido, examina-se o cuidado sob três perspectivas conceituais: como categoria ontológica, como categoria genealógica e como categoria crítica. A hermenêutica realizada na interface dessas três perspectivas permite apontar direções onde parece produtivo um esforço de reconstrução das práticas de saúde: um ativo movimento de profissionais e serviços de saúde no sentido de se voltarem ativamente à presença do outro no espaço assistencial, a otimização e diversificação das formas e qualidade da interação eu-outro nesses espaços e o enriquecimento dos horizontes de saberes e fazeres em saúde numa perspectiva decididamente interdisciplinar e intersetorial.

PALAVRAS-CHAVE: Promoção da saúde; prática de saúde pública.

* Trabalho apresentado ao VII Congreso Latinoamericano de Ciencias Sociales en Salud, em Angra dos Reis/RJ, de 19 a 23 de Outubro de 2003.

${ }^{1}$ Professor do Departamento de Medicina Preventiva da Faculdade de Medicina da Universidade de São Paulo (FMUSP). <jrcayres@usp.br> 


\section{A Saúde Pública em reconstrução}

Assistimos em tempos recentes à emergência de uma série de novos discursos no campo da saúde pública, mundial e nacionalmente, tais como a promoção da saúde, vigilância da saúde, saúde da família, redução de vulnerabilidade, entre outros. Tais discursos revelam a vitalidade conceitual da saúde pública deste início de milênio e traz ao debate diversos convites à renovação das práticas sanitárias. Contudo, uma efetiva consolidação dessas propostas e seu mais conseqüente desenvolvimento parece-nos depender de transformações bastante radicais no nosso modo de pensar e fazer saúde, especialmente em seus pressupostos e fundamentos. Acreditamos que há uma série de aspectos filosóficos que precisam ser revisitados para que, aos avanços conceituais já alcançados, possam corresponder transformações práticas mais expressivas.

É nesta condição de uma desconstrução teórica, com vistas a contribuir para a reconstrução em curso nas práticas de saúde, que se quer trazer ao debate a presente reflexão sobre o Cuidado. Não se trata de somar mais um discurso àqueles acima listados; a discussão aqui proposta está longe de pretender ter o caráter aplicado que os caracteriza. Trata-se de compreender as práticas de saúde, inclusive aquelas que constituem o substrato dos seus discursos renovadores, sob uma determinada perspectiva que, se feliz em seus propósitos, poderá agregar-se ao esforço de adensamento conceitual e filosófico desse novo sanitarismo.

\section{O Cuidado como categoria ontológica}

Normalmente quando se fala em cuidado de saúde, ou cuidado em saúde, atribui-se ao termo um sentido já consagrado no senso comum, qual seja, o de um conjunto de procedimentos tecnicamente orientados para o bom êxito de um certo tratamento. Contudo, não é nem no sentido de um conjunto de recursos e medidas terapêuticas, nem naquele dos procedimentos auxiliares que permitem efetivar a aplicação de uma terapêutica, que queremos nos remeter à questão. Trataremos aqui do cuidado como um constructo filosófico, uma categoria com a qual se quer designar simultaneamente, uma compreensão filosófica e uma atitude prática frente ao sentido que as ações de saúde adquirem nas diversas situações em que se reclama uma ação terapêutica, isto é, uma interação entre dois ou mais sujeitos visando o alívio de um sofrimento ou o alcance de um bem-estar, sempre mediada por saberes especificamente voltados para essa finalidade.

Para procedermos a esta construção conceitual, vamos iniciar por uma breve exploração da categoria cuidado tal como proposta em "Ser e Tempo", por Martin Heidegger (1889-1976), base de uma primeira delimitação de alguns dos principais pressupostos filosóficos nos quais nos apoiaremos.

Em Ser e Tempo, Heidegger se vale de uma antiga fábula de Higino para argumentar acerca da situação simultaneamente contingente $e$ transcendente da condição humana. O dasein, ou "ser-aí", construção com a qual caracteriza a existência humana, é um "estar lançado" num mundo que, por sua vez, só é percebido enquanto tal na (e por meio da) atividade




"projetiva" humana, isto é, da tripartição temporal da consciência do ser (em presente, passado e futuro), efetivada e possibilitada no e pelo ato de atribuir significado às experiências pretéritas, a partir de uma vivência atual, entendida como o devir de um projeto existencial. Nesta dialética de presente, passado e futuro, o humano surge como criador e criatura da existência, numa construção sempre em curso, que tem como substrato a linguagem e como "artesão" o cuidado (sorge). Em sua incessante atividade, o cuidado molda, a partir do mundo e contra a sua dissolução nesse mundo, as diversas formas particulares da existência (Heidegger, 1995).

Nada melhor, porém, para nos reportarmos à complexa construção heideggeriana que recorrermos, também nós, ao poder expressivo da alegoria de Higino:

Certa vez, atravessando um rio, Cuidado viu um pedaço de terra argilosa: cogitando, tomou um pedaço e começou a the dar forma. Enquanto refletia sobre o que criara, interveio Júpiter. $\mathrm{O}$ Cuidado pediu-lhe que desse espírito à forma de argila, o que ele fez de bom grado. Como Cuidado quis então dar seu nome ao que tinha dado forma, Júpiter proibiu e exigiu que fosse dado seu nome. Enquanto Cuidado e Júpiter disputavam sobre o nome, surgiu também a terra (tellus) querendo dar o seu nome, uma vez que havia fornecido um pedaço do seu corpo. Os disputantes tomaram Saturno como árbitro. Saturno pronunciou a seguinte decisão, aparentemente equitativa: 'Tu, Júpiter, por teres dado o espírito, deves receber na morte o espírito e tu, terra, por teres dado o corpo, deves receber o corpo. Como porém foi o Cuidado quem primeiro o formou, ele deve pertencer ao Cuidado

${ }^{2}$ Na tradução brasileira da Editora Vozes o termo "Sorge" é traduzido como Cura, sinônimo de Cuidado. Evitamos usar aqui esse termo para não confundir com curar no sentido médico de eliminar a doença. enquanto viver. Como, no entanto, sobre o nome há disputa, ele deve se chamar 'homo', pois foi feito de humus (terra)'. (Heidegger, 1995, p.263-4) ${ }^{2}$

Há diversas e riquíssimas aproximações hermenêuticas a essa alegoria, tal como feito por Heidegger $e$ por seus inúmeros comentadores $e$ prosseguidores. Longe de nós a intenção de inventariarmos todas elas, mas será importante destacar alguns aspectos relevantes para a discussão que faremos acerca do cuidado no âmbito específico da saúde:

Movimento. Um dos primeiros elementos que vemos presente na alegoria é o movimento. O cuidado move-se no leito do rio e é movendo-se que percebe a argila. Ele não vai em busca da argila, nem a argila chega até ele. $\mathrm{O}$ interesse e a possibilidade de moldar uma forma humana devém do encontro com a argila no movimento mesmo de atravessar o rio. Este elemento da alegoria aponta para aspecto fundamental na construção de nossas identidades de seres viventes, que é o caráter pragmático da nossa construção de identidades. Ou seja, nossas identidades não são construções a priori, inscritas como um destino inexorável para nossas biografias no momento em que nascemos. Esta identidade vai sendo construída no e pelo ato de viver, de por-se em movimento pelo mundo.

Interação. A alegoria é permeada de interações. São as interações que 
constróem a sua trama. Interação do cuidado com a argila, transformando-a em criatura; do cuidado e sua criatura com Júpiter, o que transforma a criatura num ser vivente e, no mesmo ato, faz de cuidado e Júpiter contendores, portadores de diferentes projetos para o ser vivente; interação da terra com os três, aumentando a contenda e tornando mais complexa a nomeação do ser vivente; finalmente Saturno, o senhor do tempo, interagindo com todos e determinando o lugar de cada um.

Identidade e alteridade. Um aspecto muito relevante das diferentes interações é que as identidades existenciais só se estabelecem no ato mesmo dessas interações. $O$ cuidado se faz artesão em presença da argila $e$ a argila só tem sua plasticidade atualizada por força do cuidado. Do encontro do artesão com a argila surge a criatura que, sendo produto da existência do artesão e da argila, não é mais nem artesão nem argila. Quando a criaturaforma ganha existência, coloca-se o problema da falta do espírito, que acaba por resolver-se com Júpiter, que se faz origem do espírito vivente, fazendo da criatura um ser vivente e da terra a origem do corpo de um ser vivente. A identidade de cada um se faz sempre, portanto, na presença de seu outro. A alteridade de cada um se define sempre pela construção de uma identidade, e vice-versa.

Plasticidade. Na base de todo o movimento $e$ de todas as identidades $e$ alteridades criadas pelo movimento, encontramos na alegoria a plasticidade da argila. Não fosse plástica a matéria de nossa existência, não fosse sujeita à transformação, à moldagem, não haveria a existência. Não haveria, porque não se teria concebido e criado o ser vivente, mas também porque não haveria a possibilidade de sua dissolução, de sua finitude, de sua contínua recriação. O cuidado tem a "posse" do ser vivente porquanto e enquanto o mantenha vivo, porquanto e enquanto sustente sua existência (matéria/ forma(espírito) contra a dissolução.

Projeto. Toda a plasticidade da argila, por sua vez, não poderia ter posto a trama da alegoria em movimento, ter realizado seu papel de efetivar interações e identidades, se não fosse o potencial criador, a capacidade de conceber e construir projetos própria ao cuidado. É porque antevê na plasticidade experimentada na argila a possibilidade de lhe dar a forma humana, e porque interage com a argila na medida capaz de conferir à sua plasticidade a forma antevista, que o cuidado gera o ser vivente. Daí Heidegger sustentar que o Ser do humano é cuidado. É projetar e, ao mesmo tempo, ser o "curador" do projeto.

Desejo. Não se pode perder de vista, ainda, um outro elemento fundamental na tessitura da trama da alegoria, que é o fato de que nenhum dos personagens age de forma completamente determinada. Cuidado cogita dar forma à argila que encontra, e cria uma forma. Refletindo sobre sua criação resolve dar-lhe espírito. Júpiter é convidado a soprar o espírito. A Júpiter agrada essa idéia, e o faz. Cuidado quis nomear a criatura, Júpiter proibiu e exigiu dar o seu nome, a mesma coisa quis a Terra. Ou seja, é do encontro desejante com as circunstâncias que se origina o ser vivente. É de um imponderável cogitar que surge o projeto, e é da realização do projeto que nasce a resolução de soprar o espírito. Por fim, a intenção de nomear a existência, de tomá-la para si, emerge como pura expressão de um livre e 
imponderável desejo de manifestação, de presença. Desejo de presença que a alegoria mostra fluir das dimensões corpóreas e espirituais de nossa existência, tanto quanto de nossa aspiração de dar um sentido existencial a ambas, gerando mútuos convites, resistências e conflitos entre o eu e o outro.

Temporalidade. É Saturno, senhor do tempo, que arbitra tais aspirações materiais e espirituais, confiando à habilidade artesã de um projeto de vida a tarefa de gerir a presença de cada uma no devir da existência. O Ser é (do) cuidado, mas será (do) cuidado apenas enquanto seguir sendo. É sempre na perspectiva do fluxo do tempo, do devir da existência, que faz sentido falar de cuidado, ao mesmo tempo que o cuidado é, em si mesmo, condição de possibilidade dessa tripartição temporal e deveniente da existência.

Não-causalidade. Que estranho personagem, então, é o cuidado! Ele não é o Ser, mas sem ele não há Ser; ele não é a matéria nem o espírito, mas sem ele a matéria não está para o espírito nem o espírito para a matéria; ele é uma dádiva do tempo, mas o tempo deve a ele sua existência. Estas delicadas dialéticas emergem da alegoria do cuidado como uma indicação de que não podemos explicar a existência nos termos de causa e efeito com que aprendemos a nos apropriar racionalmente de certas dimensões dessa existência. Não é possível produzirmos uma externalidade tal que nos permita estabelecer qualquer um dos personagens da alegoria como condição necessária e suficiente para a existência do outro, como não é possível sequer pensar a identidade de qualquer um deles sem a presença de seu outro. Também não é possível pensar o que antecede e o que sucede, já que a temporalidade só se manifesta como tal a partir da coexistência de todos. Nesse sentido, o cuidado exige ser pensado como "compossibilidade", só podendo ser compreendido como um "círculo hermenêutico" (Gadamer, 1991), no qual cada parte só ganha sentido numa totalidade e a totalidade tem seu sentido imediata e radicalmente dependente de cada uma de suas partes.

Responsabilidade. Mas esse "sem começo nem fim", que caracteriza o

${ }^{3}$ Stein destaca que as repercussões da ontologia existencial heideggeriana vão se fazer sentir em praticamente todo o espectro filosófico da contemporaneidade: atingiu a

fenomenologia husserliana (de onde partiu); transformou filosofia analítica, com Ryle; impactou o intento lógicofilosófico de Wittengenstein, sendo decisivo para as sua Investigações; impactou também tradição hegelianomarxista das escolas de Budapeste e de Frankfurt; por fim desdobrou-se na hermenêutica filosófica, de Gadamer. círculo hermenêutico, não levaria a um total relativismo? Esse relativismo não é conflitante com a idéia de uma ontologia, isto é, não seríamos nós conduzidos por essa visão circular até um completo indeterminismo e agnosticismo acerca do Ser? E se é assim, como encontrar numa alegoria uma narrativa, composta de uma trama, com começo, meio e fim - recurso tão feliz para a compreensão da existência? No âmbito da filosofia, esse aparente paradoxo de Heidegger significa, na verdade, talvez o mais relevante giro paradigmático contemporâneo - a ponto de Stein (1988) afirmar que o século XIX filosófico só termina em 1927, com a publicação de "Ser e Tempo" 3 . A grande novidade desse giro foi a superação da dicotomia entre transcendência e imanência, entre fundacionalismo e relativismo, entre sujeito e objeto. Heidegger mostra com Ser e Tempo que a relação, já dada e inseparável, de homem e mundo torna coincidentes a indagação acerca da existência (ontologia) e do conhecimento (epistemologia). $\mathrm{O}$ conhecimento do mundo é já um modo de ser no mundo, e não um distanciamento do mundo. A transcendência é, portanto, um plano de imanência, desde o qual o humano se constrói conhecendo(-se). É, portanto, 
sem sentido a busca ad infinitum do fundamento último do conhecimento do Ser, já que é na circularidade hermenêutica que mais fecundamente o Ser pode vir a conhecer-se. E Heidegger propõe o cuidado como a categoria que mais expressivamente consegue nos colocar em sintonia com esse plano de imanência, sem começo nem fim, no qual o ser do humano resulta de sua ocupação de si como resultado de si. Ora, nesse sentido, a existência tem, sim, um sentido, embora não como trajeto linear; tem uma causação, mas não no sentido causalista de uma cadeia onde um antecedente determina um sucesso, que é um evento distinto do seu antecedente. Podemos entender tanto o sentido como a causação na ontologia existencial como o "tomar-se para si" do dasein, que não é outra coisa que o sentido mais radical da idéia de "responsabilizar-se". A responsabilidade tem aqui o duplo $e$, de novo, inseparável sentido de responder por si e responder para si (Grondin, 1999). Cuidar não é só projetar, é um projetar responsabilizandose; um projetar porque se responsabiliza. E não é por outra razão que Saturno concede ao cuidado a posse da sua criatura porquanto e enquanto se responsabilizar por sua existência.

Apesar do excessivo grau de abstração desse plano de conceituação ontológico-existencial do cuidado, toda a discussão que se pretende fazer adiante acerca do cuidado em saúde assenta-se sobre essas bases. O que se quer propor resulta intrinsecamente do aceite ao convite à ontologia existencial, da afinação ao giro paradigmático aí efetuado. A centralidade hermenêutica da categoria cuidado no plano filosófico acima exposto e no plano aplicado a que se quer chegar não constitui, absolutamente, mera coincidência: movimento, interação, identidade/alteridade, plasticidade, projeto, desejo, temporalidade, não-causalidade e responsabilidade serão elementos que reencontraremos na discussão do cuidado quando passarmos ao plano das práticas de saúde. Antes de passarmos a esse plano, contudo, será necessário nos determos, ainda que de forma sucinta, num patamar intermediário de reflexão acerca do cuidado. Trata-se de examinar uma segunda construção conceitual de relevância para nossos propósitos, que trata do cuidado como expressão de formas de vida da civilização ocidental. Trata-se da categoria foucaultiana do cuidado de si (Foucault, 2002).

\section{O Cuidado como categoria genealógica}

Em seu processo de investigação genealógica da microfísica do poder, Michel Foucault identificou na sexualidade um campo de fecundas possibilidades. Partindo da polêmica tese de que a moral sexual vitoriana não era o paradigma de uma cultura de sublimação da sexualidade, mas, ao contrário, constituía o ápice de um processo de crescentes interesse e intervenção sobre o assunto, Foucault localiza, em torno do século II da Era Cristã, a emergência de uma "arte da existência" inteiramente nova. A ela Foucault chamou de "o cuidado de si" (Foucault, 2002).

Cabe lembrar que, ao longo dos três volumes da História da Sexualidade, o objeto central do filósofo francês não é tanto a sexualidade, em si mesma, quanto a genealogia de uma ética ocidental, entendida não como um conjunto de princípios e pressupostos universais, à moda kantiana, mas como uma espécie de tecnologia que emerge historicamente da experiência 
social, na forma de saberes e práticas voltados para a construção do lugar do eu e do outro na complexa teia de suas interações, nos planos público $e$ privado. É nesta perspectiva que a categoria "cuidado de si" é definida, dando-nos conta de um movimento de construção, manutenção $e$ transformação da identidades dos indivíduos na civilização ocidental cristã, entendidas por Foucault como "tecnologias do si". Nesse processo, o conhecimento de si, imperativo de qualquer civilização que possamos conceber, passa a especificar, nesse caso particular, formulações do tipo: Que fazer de si mesmo? Que trabalho operar sobre si? (Foucault, 1997).

Ainda que não tenha sido seu objetivo fazer a história do cuidado de si, Foucault não deixa de ser um historiador dessa tecnologia social quando busca estabelecer sua genealogia. Nesse sentido, não hesita em apontar o período que vai do século I a.C. ao século II d.C. como aquele de maior desenvolvimento desse dispositivo. Ao demonstrar sua presença já neste período, ainda que não pudesse afirmar estar situada aí sua primeira formulação, Foucault tem o material suficiente para argumentar que a gênese do cuidado de si e suas implicações do ponto de vista biopolítico é anterior ao capitalismo e à moral burguesa, embora nesses contextos possa ter assumido importância particular.

Foucault aponta que a idéia de ocupar-se consigo é bem antiga na cultura grega, estando presente, conforme relato de Plutarco, já no ideal do cidadão espartano de treinamento físico e guerreiro em detrimento do cultivo da terra. Ou na afirmação de Ciro, segundo Xenofonte, de que toda a glória decorrente dos grandes feitos de um homem de nada valiam se fosse à custa do sacrifício do ocupar-se consigo mesmo. Sustenta, contudo, que, até então, este ocupar-se de si tinha a conotação de uma prerrogativa (de alguns), ou mesmo de um privilégio, uma dádiva. Mostra, então, que é com o Sócrates do "Alcebíades", ou da "Apologia", que esse ocupar-se de si vai ganhar a forma de um cuidado de si, adquirindo progressivamente "as dimensões e formas de uma verdadeira 'cultura de si'.

Por essa expressão é preciso entender que o princípio do cuidado de si adquiriu um alcance bem geral: o preceito segundo o qual convém ocupar-se consigo mesmo é em todo caso um imperativo que circula entre numerosas doutrinas diferentes; ele também tomou a forma de uma atitude, de uma maneira de se comportar, impregnou formas de viver; desenvolveu-se em procedimentos, em práticas e em receitas que eram refletidas, desenvolvidas, aperfeiçoadas e ensinadas; ele constituiu assim uma prática social, dando lugar a relações interindividuais, a trocas $e$ comunicações, e até mesmo a instituições; ele proporcionou, enfim, um certo modo de conhecimento e a elaboração de um saber. (Foucault, 2002, p.50)

A epimeleia heautou, ou cura sui, ou essa arte de viver sob o cuidado de si, desenvolve-se, assim, sob o signo do platonismo, como um aperfeiçoamento da alma com auxílio da razão para que se possa levar a melhor vida, da mesma forma como se cuida dos olhos para melhor ver, ou dos pés para 
melhor correr. Já entre os epicuristas pregava-se o cuidado de si como um recurso à filosofia para garantir "a saúde da alma". Sêneca dará passos mais largos rumo à conformação da arte existencial do cuidado de si ao defender que
A mais acabada elaboração filosófica desse tema, segundo Foucault, será feita, porém, por Epicteto, que chega a definir o ser humano como "o ser a quem foi confiado o cuidado de si" (Foucault, 2002, p.53), recebendo de Deus, com essa finalidade, a faculdade da razão. E a recomendação do cuidado de si não tem em vista apenas o modo de vida do filósofo, do indivíduo que dedica sua vida à sabedoria. Conforme Apuleu, aperfeiçoar a própria alma com a ajuda da razão é uma regra igualmente necessária para todos os homens.

Vê-se, assim, como o cuidado de si constitui-se, simultaneamente, como um atributo e uma necessidade universal dos seres humanos, regido por princípios de aplicação geral, embora orientados para uma prática de escopo e responsabilidades absolutamente individuais. Não mais um prazer ou uma prerrogativa, não cuidar-se é sucumbir, e para não sucumbir era preciso conhecer a verdade que a razão a todos podia dar acesso.

Esses preceitos, como já indicado, desdobraram-se para além desse caráter doutrinário, conformando um conjunto bem especificado de ações. Como Foucault adverte, o termo epimeleia designa não apenas uma preocupação, mas um conjunto de ocupações, um labor. Era com esse mesmo termo que se designava as atividades de um dono de casa, as tarefas de um príncipe que vela por seus súditos, ou os cuidados que se deve ter para com um doente ou ferido. Este mesmo sentido está presente também na alegoria de Higino, como vimos: o cuidado se curva, toma a argila do leito do rio, molda com suas mãos a forma humana e recebe de Saturno o privilégio/obrigação de zelar pela vida de sua criatura.

Esta vinculação com o labor, com essa atividade relacionada às necessidades vitais, com a vita activa, conforme Arendt (1981), estabeleceu precocemente uma correlação muito estreita entre o cuidado de si e a Medicina. Embora não fosse uma preocupação exclusiva sua, não há dúvida de que o conjunto de atividades que constitui o labor implicado no cuidado de si - exercícios, dietas, regimes de sono e vigília, atividade sexual, cuidados corporais, meditações, leituras etc. - serão formulados principalmente por médicos. Se somarmos a isso que o restabelecimento da saúde é também parte dos imperativos do cuidado de si, maior razão teremos de atribuir à Medicina o papel de grande responsável pelo desenvolvimento da epimeleia heautou. Galeno (129-199) é aqui a figura paradigmática. Ao galenismo não apenas pode ser creditado grande parte do desenvolvimento das tecnologias do cuidado de si (Foucault, 2002) como, na mesma direção e em sentido inverso, a ele se deve forte e influente identificação da Medicina

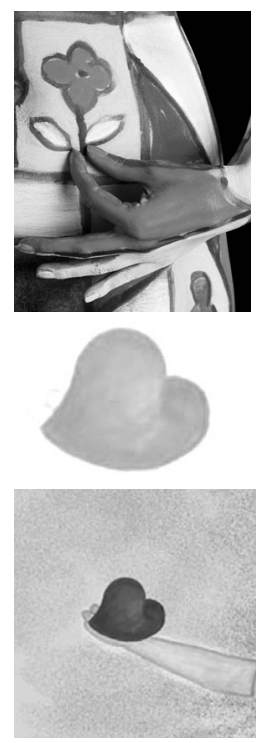


ocidental ao racionalismo individualizante e intervencionista que marca tais tecnologias. Com efeito, a partir de Galeno o alcance da saúde passou a depender, de um lado, do diagnóstico de cada constituição individual, apreendida por meio da aplicação racional e sistemática de categorias que expressavam leis universais da natureza (teoria dos humores) e, de outro lado, de uma ativa intervenção do médico sobre os fatores perturbadores ou obstaculizadores do melhor arranjo desta constituição (Ackerknecht, 1982; Sigerist, 1990).

Abandonaremos neste ponto o estudo de Foucault, pois não nos interessa aqui as conseqüências que o filósofo extrai da sua genealogia quanto às regulações que se farão sobre a sexualidade $e$ a sociabilidade por intermédio das tecnologias do si. Basta-nos tão somente destacar as relações mutuamente esclarecedoras e fecundantes entre o desenvolvimento do discurso e da prática médica ocidentais e uma ontologia existencial fundada na idéia de cuidado. Em síntese, Heidegger possibilitou-nos uma autocompreensão existencial da condição humana como cuidado. Foucault nos mostra o desenvolvimento do cuidado de si como uma forma de vida no ocidente cristão. O cuidado de si possibilita, assim, enraizar genealogicamente o plano de imanência da ontologia heideggeriana, ao mesmo tempo em que o dasein abre-nos a possibilidade de conferir um sentido existencial à genealogia foucaultiana. É tirando proveito dessa mútua fecundação, da possibilidade de nos argüirmos do valor existencial das tecnologias do si como forma de vida, que buscaremos nos indagar a respeito das práticas de saúde contemporâneas, dos alcances, limites $e$ implicações das formas atuais de cuidado em saúde. Cabe, nesse sentido, nos perguntarmos: até que ponto esse labor individualista e "pan-racionalista" segue instruindo as práticas de saúde contemporâneas? Em que tecnologias específicas se organiza, se é que se organiza? Até que ponto atinge nossas práticas de saúde pública? É possível identificar outros tipos de tecnologia, outras "artes da existência", outros projetos existenciais nas propostas contemporâneas para as práticas de saúde pública?

\section{O Cuidado como categoria crítica}

O terceiro plano de aproximação à questão do cuidado a que agora nos remeteremos diz respeito ao cuidado como modo de interação nas e pelas práticas de saúde nos seus moldes contemporâneos, restringindo-nos agora às tecnologias já configuradas como o campo institucional das práticas de saúde.

Embora o próprio Foucault (2001) tenha demonstrado que a Medicina, nas sociedades capitalistas, tornou-se uma Medicina social, isto é, que sob o capitalismo ampliou-se a esfera de cognição e intervenção normativa dos saberes e fazeres da saúde ao campo das relações sociais, este processo não parece ter afetado radicalmente o caráter individual-universalista do cuidado de si, especialmente quando se trata das ações de assistência médica. Com efeito, Foucault mesmo nos mostra que é sobre o corpo dos indivíduos que as tecnologias do social são aplicadas, disciplinando-os, regulando-os $e$ potencializando-os como força produtiva. Quando pensamos especificamente nas tecnologias mais imediatamente aplicadas aos coletivos humanos, 
organizados em torno da higiene vemos o mesmo se repetir. Ainda que tenham experimentado um momento mais caracteristicamente coletivo, público e politicamente consensual de conhecimento $e$ intervenção normativas na saúde, a higiene pública $e$ a higiene social cederam rapidamente lugar a uma higiene centrada na tradução cientificista $e$ individualmente centrada das tecnologias de cuidado em saúde. Com efeito, desde meados do século XIX a racionalidade que orientou o horizonte normativo da saúde pública passou mais e mais a ater-se a uma racionalidade estritamente científica $e$ as suas correspondentes estratégias reguladoras orientaram-se também progressivamente para uma gestão individual dos riscos à integridade e desempenho funcional do corpo (Ayres, 1997).

Foge aos objetivos deste ensaio, no entanto, uma maior fundamentação dessa tese da persistência do caráter individual-universalista do cuidado em saúde. O que nos importa aqui é reter esta tese como o pano de fundo de recentes problematizações desse cuidado no âmbito de suas configurações técnicas e institucionais, em meio às quais se inserem as nossas próprias. Tais problematizações consistem de um variado conjunto de reflexões críticas sobre as tecnologias da saúde que, sob diferentes perspectivas, tratam da organização de ações e serviços de saúde, da formulação de políticas de saúde, das relações médico-paciente, das relações serviçospopulação, das relações entre os diversos profissionais nas equipes de saúde, entre outros aspectos (Schraiber et al., 2000; Pinheiro \& Mattos, 2003; Czeresnia \& Freitas, 2003). Entre essas diversas possibilidades de aproximação crítica, vamos nos deter especificamente nas tecnologias de assistência à saúde, aspecto que de certa maneira atravessa todas as outras, mas que, sem dúvida, diz respeito mais imediatamente ao encontro terapêutico propriamente dito.

As recentes transformações da Medicina contemporânea rumo à progressiva cientificidade e sofisticação tecnológica apresenta efeitos positivos e negativos, já relativamente bem conhecidos. De um lado, identifica-se como importantes avanços a aceleração e ampliação do poder de diagnose, a precocidade progressivamente maior da intervenção terapêutica, o aumento da eficácia, eficiência, precisão e segurança de muitas dessas intervenções, melhora do prognóstico e qualidade de vida dos pacientes em uma série de agravos. Como contrapartida, a autonomização e tirania dos exames complementares, a excessiva segmentação do paciente em órgãos $e$ funções, o intervencionismo exagerado, o encarecimento dos procedimentos diagnósticos e terapêuticos, a desatenção com os aspectos psicossociais do adoecimento e a iatrogenia transformam-se em evidentes limites.

Acompanhando a observação desses limites, passou a ser comum a referência a uma crise da Medicina, crise que, no campo em que

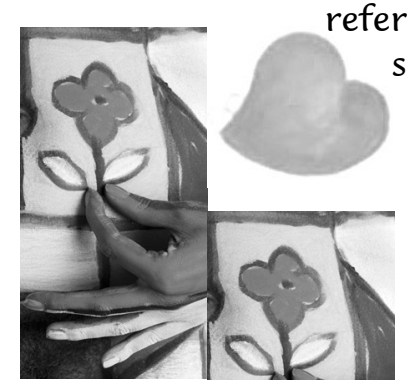
situamos esta reflexão, identifica-se fundamentalmente com o que Schraiber (1997a) caracterizou como uma "crise de confiança", referindo-se ao fato de que o paroxístico progresso tecnológico da Medicina acarretou profunda insegurança quanto à adequação prática $e$ correção moral do que está sendo feito nas práticas 
terapêuticas, por todas as razões acima listadas. Nesse sentido, destaca-se, entre outros problemas, uma progressiva incapacidade das ações de assistência à saúde de se provarem racionais, de se mostrarem sensíveis às necessidades das pessoas e se tornarem cientes de seus próprios limites.

Uma resposta freqüente ao problema, apoiada na tradicional visão da assistência à saúde como misto de ciência e arte, é a de que o problema estaria num suposto esquecimento da dimensão arte. Haveria muita tecnologia científica e pouca arte na Medicina contemporânea - muita tecnociência porque pouca arte, ou pouca arte porque muita tecnociência.

Embora se aproxime de aspectos fulcrais do problema, essa forma de colocar a questão não parece satisfatória. É lícito afirmar que, em nossos dias, falar da arte ou falar da tecnociência da Medicina é quase a mesma coisa. Não há, no âmbito da herança cultural em que nos movemos, arte sem tecnociência nas ações de assistência médica. A tecnociência médica incorpora a arte médica, molda essa arte, expressa essa arte. A arte médica, por sua vez, reclama a tecnociência, alimenta-se dela, transfigura-se nela. Quando um profissional da saúde introduz entre seus procedimentos propedêuticos as evidências produzidas por uma Medicina Baseada em Evidências, ele está sacrificando a arte à tecnociência ou está produzindo arte médica como tecnociência? Quando as ciências e tecnologias médicas tornam-se mais e mais diversificadas e especializadas, estão elas procurando uma condição de pureza $e$ autonomia científicas ou estão respondendo à diversificação de juízos requeridos para a tomada de decisões na assistência? Pensamos poder assumir como verdadeira a segunda posição em ambos os casos. Não parece, por isso, interessante polarizar "arte $x$ ciência". Devemos, isto sim, problematizar de forma indissociável o par "arte-tecnociência". Ou seja, o que devemos examinar é o significado desse lugar destacado e determinante que a tecnociência passou a ocupar na arte da assistência. O que é essa arte tecnocientífica? O que são essas ciências completamente dependentes da arte de assistir à saúde? Por que a tecnociência da assistência à saúde tem sido acusada de ser irracional, desumana, onipotente?

Temos uma proposição hipotética a respeito dessa última indagação, que pode ser formulada como a afirmação de que a atual crise de legitimidade das formas de organização do cuidado em saúde, isto é, a falta de confiança nos seus alcances técnicos e éticos, decorre do progressivo afastamento da arte tecnocientífica da Medicina em relação aos projetos existenciais que the cobram participação e lhe conferem sentido. Dito de outra forma, é como se a terapêutica estivesse perdendo seu interesse pela vida, estivesse perdendo o elo de ligação entre seus procedimentos técnicos e os contextos e finalidades práticos que os originam e justificam. Narcísica, a Medicina tecnocientífica encantou-se consigo mesma. Não cessa de se olhar no espelho, espelho que se desdobra ad infinitum, mostrando sempre mais à arte como ela pode ser poderosa com a ciência e à ciência como são ilimitados seus potenciais artísticos. O conflito entre esses dois pólos não passa, portanto, de um artifício de imagem: o que parece uma negação de um ao outro não é mais que a busca do melhor ângulo para o mesmo reflexo. Uma mesma imagem busca incessantemente a si mesma, como dois espelhos antepostos. Arte e ciência oferecem uma à outra um enorme poder e, nesse encantamento 
mútuo, deixaram muitas vezes de se perguntar: poder de quem, poder porque, poder para quê?

Conforme nos mostrou Heidegger (1995), o querer, o julgar, o conhecer e o fazer são diferentes expressões de um mesmo "ser-aî". A compreensão sobre quem tem poder de fazer o que e porque é portanto fundamental para as relações entre a tecnociência médica e a vida da qual faz parte. Ao tornar-se quase impermeável a questões acerca do que seja, afinal, a saúde que persegue; ao limitar a um mínimo o lugar dos desejos e da busca de felicidade como critérios válidos para avaliar o sentido das práticas; ao não se preocupar suficientemente com a natureza e os mecanismos da construção dos consensos intersubjetivos que orientam seus saberes (a práxis científica) e suas práticas (a práxis médica), a assistência à saúde começa a se tornar problemática, inclusive para seus próprios criadores, enfrentando crises econômicas, crises políticas mas, especialmente, as já citadas crises de legitimidade.

Quando pensamos na assistência à saúde, vem-nos de imediato à mente a aplicação de tecnologias para o bem estar físico e mental das pessoas. Em geral a formulação é simples: a ciência produz o conhecimento sobre as doenças, a tecnologia transforma esse conhecimento em saberes $e$ instrumentos para a intervenção, os profissionais de saúde aplicam esses saberes e instrumentos e produz-se a saúde. Precisamos considerar que a direção inversa também é verdadeira: que o modo como aplicamos e construímos tecnologias e conhecimentos científicos determina limites para o que podemos enxergar como necessidades de intervenção em saúde. Precisamos ter claro também que nem tudo que é importante para o bem estar pode ser imediatamente traduzido e operado como conhecimento técnico. E por fim, mas fundamental, precisamos estar atentos para o fato de que nunca, quando assistimos à saúde de outras pessoas, mesmo estando na condição de profissionais, nossa presença na frente do outro se resume ao papel de simples aplicador de conhecimentos. Somos sempre alguém que, percebamos ou não, está respondendo a perguntas do tipo: "O que é bom pra mim?", "Como devo ser?", "Como pode ser a vida?" (Mendes Gonçalves, 1994; Schraiber, 1997b).

Ora, se tecnologia não é apenas aplicação de ciência, não é simplesmente um modo de fazer, mas é também, enquanto tal, uma decisão sobre quais coisas podem e devem ser feitas, então nós temos que pensar que nós, profissionais de saúde, estamos construindo mediações, estamos escolhendo dentro de certas possibilidades o que devem querer, ser e fazer aqueles a quem assistimos - e nós próprios. Por outro lado, se assumimos também que as respostas necessárias para alcançar a saúde não se restringem aos tipos de pergunta que podem ser formuladas na linguagem da ciência, então a ação em saúde não pode se restringir à aplicação de tecnologias. Nossa intervenção técnica tem que se articular com outros aspectos não tecnológicos. Não podemos limitar a arte de assistir apenas à criação $e$ manipulação de "objetos".

Na qualidade de portador de uma demanda de saúde, qualquer indivíduo é, de fato, potencial "objeto de conhecimento e intervenção". É isso que se espera das ciências e dos serviços de saúde. Contudo, nada, nem ninguém, 
${ }^{4}$ Para diferenciar o uso deste termo nesta perspectiva reconstrutiva, isto é, de um "ideal regulador" (Habermas, 1990), o grafaremos sempre com inicial maiúscula.

pode subtrair a esse mesmo indivíduo, como aspirante ao bem-estar, a palavra última sobre suas necessidades. Encontrando suas ressonâncias profundas nas suas dimensões ontológico-existenciais, é preciso que o cuidado em saúde considere e participe da construção de projetos humanos. Como vimos, para cuidar há que se sustentar, ao longo do tempo, uma certa relação entre a matéria e o espírito, o corpo e a mente, moldados a partir de uma forma de vida que quer se opor à dissolução, que quer garantir e fazer valer sua presença no mundo. Então é forçoso, quando cuidamos, saber qual é o projeto de felicidade, isto é, que concepção de vida bem sucedida orienta os projetos existenciais dos sujeitos a quem prestamos assistência. Como aparece ali, naquele encontro de sujeitos no e pelo ato de cuidar, os projetos de felicidade de quem quer ser cuidado? Que papel desempenhamos nós, os que queremos ser cuidadores, nas possibilidades de conceber essa felicidade, em termos de saúde? Que lugar podemos ocupar na construção desses projetos de felicidade de cuja concepção participamos? A verdade é que raramente chegamos sequer a nos indagar sobre os projetos de felicidade daqueles indivíduos ou populações aos quais prestamos assistência, quanto mais participar ativamente de sua construção.

\section{O Cuidado ${ }^{4}$ como categoria reconstrutiva}

Atribuímos, aqui, ao Cuidado o estatuto de uma categoria reconstrutiva, querendo com isso nos referir à aposta, fundamentada na trajetória reflexiva acima descrita, de que existe uma potencialidade reconciliadora entre as práticas assistenciais e a vida, ou seja, a possibilidade de um diálogo aberto e produtivo entre a tecnociência médica $e$ a construção livre $e$ solidária de uma vida que se quer feliz, a que estamos chamando de Cuidado.

O momento assistencial pode (e deve) fugir de uma objetivação "dessubjetivadora", quer dizer, de uma interação tão obcecada pelo "objeto de intervenção" que deixe de perceber e aproveitar as trocas mais amplas que ali se realizam. Com efeito, a interação terapêutica apóia-se na tecnologia, mas não se limita a ela. Estabelece-se a partir e em torno dos objetos que ela constrói, mas precisa enxergar seus interstícios. Nesse sentido, o Cuidar põe em cena um tipo de saber que se distingue da universalidade da técnica e da ciência, como também se diferencia do livre exercício de subjetividade criadora de um produtor de artefatos. Ou seja não é a theoría nem a póiesis o espaço privilegiado do Cuidado, mas aquele que os amalgama nas interações terapêuticas, a práxis, ou atividade prática. $\mathrm{O}$ saber que se realiza aqui (se deixarmos) é algo que na filosofia aristotélica é chamado de phrónesis, ou sabedoria prática, um tipo de saber que não cria objetos, mas constitui sujeitos diante dos objetos criados no e para seu mundo (Gadamer, 1991).

Ao considerarmos verdadeiramente esse outro saber no momento assistencial, assumimos que a saúde e a doença, não são apenas objeto, mas, na condição mesma de objeto, configuram modos de "ser-no-mundo". Enquanto tal, utilizar ou não certas tecnologias,

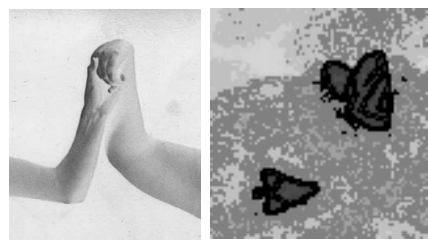

Interface - Comunic., Saúde, Educ., v.8, n.14, p.73-92, set.2003-fev.2004




desenvolver ou não novas tecnologias, quais tecnologias combinar, quais tecnologias transformar, todas essas escolhas resultam de um juízo prático, um tipo de sabedoria diferente daquela produzida pelas ciências. Trata-se de uma sabedoria que não cria produtos, não gera procedimentos sistemáticos e transmissíveis, não cria universais, posto que só cabe no momento mesmo em que os seus juízos se fazem necessários. Quando o cientista e/ou profissional da saúde não pode prescindir da ausculta do que o outro (o paciente ou os grupos populacionais assistidos) deseja como modo de vida $e$ como, para atingir esse fim, pode lançar mão do que está disponível (saberes técnicos inclusive, mas não só, pois há também os saberes populares, as convicções e valores pessoais, a religião etc.), então de fato já não há mais objetos apenas, mas sujeitos e seus objetos. Aí a ação assistencial reveste-se efetivamente do caráter de Cuidado.

Revalorizar a dignidade dessa sabedoria prática é, portanto, uma tarefa $e$ um compromisso fundamental quando se quer Cuidar. Mas isso nem sempre é fácil, porque é freqüente tomarmos o reconhecimento e a valorização desses saberes não-técnicos como obscurantismo, atraso. Isso nos parece um lamentável equívoco. Nós podemos não concordar com uma dada crença de um paciente, por exemplo, e, conversando com ele, seguirmos convictos de que essa crença não lhe beneficia, $e$ até vir a convencê-lo disso. Mas, independente de o convencermos ou sermos convencidos por ele, se simplesmente desconsiderarmos um saber nãotécnico implicado na questão de saúde com que estamos lidando, então não estaremos deixando a pessoa assistida participar de fato da ação em curso.

Ela não estará sendo sujeito. É fundamentalmente aí que está a importância do Cuidar nas práticas de saúde: o desenvolvimento de atitudes e espaços de genuíno encontro intersubjetivo, de exercício de uma sabedoria prática para a saúde, apoiados na tecnologia, mas sem deixar resumir-se a ela a ação em saúde. Mais que tratar de um objeto, a intervenção técnica se articula verdadeiramente com um Cuidar quando o sentido da intervenção passa a ser não apenas o alcance de um estado de saúde visado de antemão, nem somente a aplicação mecânica das tecnologias disponíveis para alcançar este estado, mas o exame da relação entre finalidades e meios, e seu sentido prático para o paciente, conforme um diálogo o mais simétrico possível entre profissional e paciente.

É claro que certas assimetrias podem ser desejadas, ou mesmo humanamente inexoráveis. Por exemplo, o domínio de um sem número de tecnologias e conhecimentos científicos é, na maior parte das vezes, absolutamente inviável e desinteressante para o assistido. Isto não deve servir de obstáculo, porém, a que este compreenda os significados práticos de qualquer tipo de intervenção que lhe seja proposto, nem de criar canais que lhe permitam participar de escolhas relevantes sobre o que e como produzir nas tecnologias da saúde. Outro exemplo é o lugar terapêutico de uma certa confiança "quase-incondicional" que a pessoa fragilizada por algum padecimento de saúde tende a depositar no seu cuidador, o que não precisa ser confundido com dependência ou inferioridade. Recuperar a dignidade da sabedoria prática, da phrónesis, abrir espaço para a reflexão e a negociação sobre objetivos e meios das ações em saúde, sem determinar de 
modo absoluto e a priori onde e como chegar com a assistência: eis como vemos configurarem-se o norte político $e$ as tarefas práticas de uma reconstrução das ações de saúde quando se tem o Cuidado como horizonte.

\section{O Cuidado e os desafios da reconstrução}

São diversos os desafios que se colocam para a reconstrução das práticas de saúde no sentido "reconciliador" acima apontado. Não temos aqui a pretensão de listá-los exaustivamente, tampouco de estabelecer qualquer tipo de hierarquização ou ordem de prioridades. Contudo é possível identificar alguns mais imediatamente visíveis e que agruparemos conforme três motivações fundamentais: voltar-se à presença do outro; otimizar a interação e enriquecer horizontes.

\section{Voltar-se à presença do outro}

Por tudo o que foi dito, torna-se evidente, no que se refere às tecnologias disponíveis, a necessidade de superar a restrição àquelas que trabalhem restritamente com uma racionalidade instruída pelos objetos das ciências biomédicas. Embora estas ciências ocupem lugar fundamental $e$ insubstituível, pelo tanto que já avançaram na tradução de demandas de saúde no plano da corporeidade, ao atentarmos à presença do outro (sujeito) na formulação e execução das intervenções em saúde, precisamos de conhecimentos que nos instruam também desde outras perspectivas. É assim que a tradução objetiva das identidades e aspirações dos indivíduos $e$ populações de quem cuidamos, para além da dimensão corporal realizada pelas ciências biomédicas, guarda enorme interesse para o Cuidar. Conceitos e métodos da psicologia, da antropologia, da sociologia, podem nos ajudar a compreender mais ricamente os sujeitos com os quais interagimos nas $e$ pelas ações de saúde. Muito em particular, o recurso a estas outras possibilidades objetivadoras são essenciais para superar a perspectiva individualista que exerce tão forte influência em nossas práticas de saúde, desde suas raízes gregas.

Claro que não se pode imaginar que a incorporação de outras perspectivas científicas que tratem de estruturas e processos transindividuais seja o suficiente para superar os excessos individualistas das tecnologias da saúde. Há aqui determinantes de diversas outras ordens que precisam ser considerados. Porém, se não é suficiente, certamente esse é um movimento necessário, pois tais disciplinas podem estender a fabulosa capacidade das ciências de produzir consensos intersubjetivos e instrumentalmente orientados a regiões discursivas que se ocupem de experiências coletivas, grupais, culturais, institucionais, ampliando possibilidades de aproximações tecnológicas a essas regiões. As bases científicas das tecnologias de saúde não precisam (e não devem) ficar restritas às ciências biomédicas. Um exemplo da possibilidade e relevância desse enriquecimento disciplinar na instrução de práticas de saúde, e do correlativo alargamento do escopo de suas ações, é a proposição do quadro conceitual da vulnerabilidade (Mann \& Tarantola, 1996; Ayres et al. 2003), desenvolvidas no contexto da epidemia de HIV/AIDS. O enfoque da vulnerabilidade tem se mostrado um valioso instrumento para escaparmos à 
lógica cognitivo-comportamentalista na compreensão da suscetibilidade à infecção pelo HIV e, consequentemente, tem nos permitido ampliar as intervenções preventivas para além do território e responsabilidades restritas à individualidade.

Temos também clareza, por outro lado, de que não é só na ampliação do espectro de saberes científicos que temos que trabalhar para que o outro $e$ seus contextos estejam presentes no Cuidado. Mesmo considerando as diferenças de pressupostos e métodos das diversas disciplinas, a tendência dos saberes científicos, de modo geral, é trabalhar com regularidades, com relações de determinação que serão sempre muito abstratas com referência às situações concretas que vamos encontrar no cotidiano das práticas de saúde. Por isso é preciso também um trabalho de reconstrução que se dê no espaço mesmo de operação dos saberes tecnológicos. Nesse sentido, parecenos bastante produtiva a classificação proposta por Merhy (2000) para os diferentes "estágios" de conformação e operação de tecnologias, chamando a atenção para a importância das "tecnologias leves", aquelas implicadas no ato de estabelecimento das interações intersubjetivas na efetuação dos cuidados em saúde. O espaço das tecnologias leves é aquele no qual nós, profissionais de saúde, estamos mais imediatamente colocados frente ao outro da relação terapêutica. Assim, dependendo do modo como organizamos este espaço de prática, teremos maiores ou menores chances de que, através do fluir de uma sabedoria prática por entre o mais amplo espectro de saberes e materiais tecnocientíficos disponíveis, a presença desse outro seja mais efetiva e criativa. Com preocupações desta natureza, vemos recentemente tomar forma algumas das mais importantes iniciativas no sentido de reconstrução das práticas de saúde por meio de reflexões e inovações em aspectos da maior relevância no cuidado em saúde, como acolhimento, vínculo e responsabilização na organização da assistência à saúde (Silva Jr et al., 2003).

\section{Otimizar a interação}

O espaço privilegiado das tecnologias leves nos traz a essa segunda área de motivação, que é a da otimização das interações. Teixeira (2003) chama a atenção para o fato de que o espaço das tecnologias leves pode ser entendido, por sua dimensão comunicacional, como um espaço de conversação e os serviços de saúde como complexas e dinamicamente interligadas redes de conversação. Demonstra, a partir dessa perspectiva, que os onipresentes e substantivos diálogos que entretecem todo o trabalho em saúde não conformam apenas a matéria por meio da qual operam as tecnologias, mas que a conversação, ela própria, na forma em que se realiza, constitui um campo de conformação de tecnologias. $\mathrm{O}$ autor exemplifica sua posição com a questão do acolhimento, mostrando que mais que um espaço de recepção, ou um ponto determinado de um fluxograma, o acolhimento constitui um dispositivo que pode perpassar todo e qualquer espaço $e$ momento de trabalho de um serviço de saúde. Para isso, e o mesmo raciocínio parece valer também para a questão do vínculo e da responsabilização, basta que as tecnologias de conversação sejam desenvolvidas no sentido de uma ausculta sensível - que permita em todos 
esses espaços e momentos a irrupção do outro, com suas variadas demandas - e de uma orientação assistencial voltada à integralidade do cuidado - com capacidade e agilidade de produzir algum tipo de resposta do serviço a essas demandas. Por outro lado, quanto mais tais redes de conversação forem percebidas e trabalhadas, tanto mais as vozes e demandas dos sujeitos técnicos se farão ouvir também, pois, do mesmo modo que os indivíduos $e$ populações "alvo", também os operadores da técnica se vêm limitados em sua expressão subjetiva por tecnologias instruídas por categorias excessivamente universais, abstratas e rígidas.

Instruídos por uma concepção dialógica, não apenas a sensibilidade da ausculta (bilateral) e a capacidade de resposta devem ser repensados nos serviços de saúde. A própria avaliação do que seja o bom êxito das ações desenvolvidas precisa sofrer rearranjos correspondentes. Sob este modo de ver, não faz sentido, por exemplo, enxergar necessariamente como fracasso os limitados resultados obtidos no desempenho de uma atividade, a não adesão a uma proposta de atenção ou mesmo a pouca demanda por um serviço oferecido. Desde uma compreensão dialógica das ações de saúde, todo e qualquer fracasso técnico, como também todo e qualquer êxito, admite (e reclama) ser avaliado simultaneamente quanto ao seu significado prático. Em outras palavras, é preciso que não apenas o alcance de fins, mas também a qualidade dos meios, isto é, a efetividade comunicacional das atividades assistenciais, em termos de forma e conteúdo, se incorpore como preocupação e norte do planejamento e avaliação das ações e serviços de saúde (Sala et al., 2000).

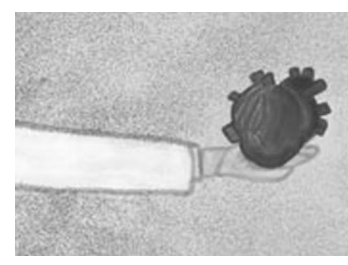

\section{Enriquecer horizontes}

Finalmente, a orientação em relação a um Cuidar efetivo, no qual a presença do outro seja ativa $e$ as interações intersubjetivas sejam ricas $e$ dinâmicas, exige que tanto a racionalidade orientadora das tecnologias quanto os âmbitos e agentes de sua operação tenham seus horizontes expandidos. É preciso superar a conformação individualista, rumo a esferas também coletivas, institucionais e estruturais de intervenção e enriquecer a racionalidade biomédica com construtos de outras ciências e outros saberes. Todos esses nortes dependem de que saiam do jargão sanitário e passem a fazer parte de efetivos rearranjos tecnológicos as surradas bandeiras da interdisciplinaridade e intersetorialidade - as quais nunca será demais endossar. A essas somaríamos outra, ainda, não tão celebrada mas já relativamente valorizada: a da pluralidade dialógica, isto é, a abertura dos espaços assistenciais a interações dialógicas por meio de linguagens outras, como a expressão artística, o trabalho com linguagens corporais e mesmo outras racionalidades terapêuticas.

Temos razões objetivas para otimismo em relação às possibilidades atuais de expansão de horizontes. Conforme dizíamos no início, há uma série de novas propostas em curso no campo da saúde, algumas ainda apenas na forma de discursos, outras já se estendendo como práticas mais consolidadas que podem contribuir nessa direção. Os Programas de Saúde da Família (PSF) dão nova base para articulações intersetoriais e promovem a entrada de novos cenários, sujeitos e linguagens na cena da assistência; a 
AYRES, J. R. C. M.

sensibilidade para os aspectos sócio-culturais do processo saúde-doença ganha novo ímpeto com a crescente ênfase dada à promoção da saúde; quadros como o da vulnerabilidade resgatam os aspectos contextuais $e$ institucionais como esfera de diagnóstico e intervenção em saúde, chamando à interação entre diferentes disciplinas e áreas do conhecimento; a vigilância da saúde incorpora novos objetos e tecnologias e, especialmente, propicia um intenso protagonismo comunitário na definição de finalidades $e$ meios do trabalho sanitário. Todas essas mudanças constituem novas interfaces dialógicas com enormes potenciais para os sentidos de reconstrução das práticas de saúde que viemos de discutir. Resta-nos agora o não pequeno desafio de fazer com que os novos discursos trazidos por e com essas recentes proposições permitam, efetivamente, reconstruir nossas práticas de saúde para que possamos sempre mais chamá-las de Cuidado.

\section{Referências}

ACKERKNECHT, E. H. A short history of Medicine. Baltimore: The Johns Hopkins University Press, 1982.

ARENDT, H. A condição humana. Rio de Janeiro: Forense-Universitária, 1981.

AYRES, J. R. C. M. Sobre o risco: para compreender a epidemiologia. São Paulo: Hucitec, 1997.

AYRES, J. R. C. M.; FRANÇA JÚNIOR, I.; CALAZANS, G. J.; SALETTI FILHO, H. C. O conceito de vulnerabilidade e as práticas de saúde: novas perspectivas e desafios. In: CZERESNIA, D.; FREITAS, C. M. (Orgs.) Promoção da saúde: conceitos, reflexões, tendências. Rio de Janeiro: Fiocruz, 2003. p.117-39.

CZERESNIA, D.; FREITAS, C. M. (Orgs.) Promoção da saúde: conceitos, reflexões, tendências. Rio de Janeiro: Fiocruz, 2003.

FOUCAULT, M. Resumo dos cursos do Collège de France (1970-1982). Rio de Janeiro: Zahar, 1997.

FOUCALT, M. O nascimento da Medicina Social. In: FOUCAULT, M. Microfísica do poder. Rio de Janeiro: Graal, 2001. p.79-98.

FOUCAULT, M. História da sexualidade. 3.ed. Rio de Janeiro: Graal, 2002.

GADAMER, H.G. Verdad y método. Salamanca: Sígueme, 1991.

GRONDIN, J. Introdução à hermenêutica filosófica. São Leopoldo: Unisinos, 1999.

HEIDEGGER, M. Ser e tempo. Petrópolis: Vozes, 1995.

MANN, J.; TARANTOLA, D. J. M. (Eds.) Aids in the world II. New York: Oxford University Press, 1996.

MENDES GONÇALVES, R. B. Tecnologia e organização social das práticas de saúde:

características tecnológicas do processo de trabalho na rede estadual de centros de saúde de São Paulo. São Paulo: Hucitec/Abrasco, 1994.

MERHY, E. E. Um ensaio sobre o médico e suas valises tecnológicas: contribuições para compreender as reestruturações produtivas do setor saúde. Interface - Comunic., Saúde, Educ., v.4, n.6, p.10916, 2000.

PINHEIRO, R.; MATTOS, R. A. (Orgs.) Construção da integralidade: cotidiano, saberes e práticas em saúde. Rio de Janeiro: IMS/UERJ-Abrasco, 2003. 
SALA, A.; NEMES, M. I. B.; COHEN, D. D. Avaliação na prática programática. In: SCHRAIBER, L. B.; NEMES, M. I. B.; MENDES GONÇALVES, R. B. (Orgs.) Saúde do adulto: programas e ações na unidade básica. São Paulo: Hucitec, 2000. p.173-93.

SCHRAIBER, L. B. Medicina tecnológica e prática profissional contemporânea: novos desafios e outros dilemas. 1997a. Tese (Livre Docência) - Faculdade de Medicina, Universidade de São Paulo, São Paulo.

SCHRAIBER, L. B. No encontro da técnica com a ética: o exercício de julgar e decidir no cotidiano do trabalho em Medicina. Interface - Comunic., Saúde, Educ., v.1, n.1, p.123-38, 1997b.

SCHRAIBER, L. B.; NEMES, M. I. B.; MENDES GONÇALVES, R. B. (Orgs.) Saúde do adulto: programas e ações na unidade básica. São Paulo: Hucitec, 2000.

SIGERIST, H. Hitos en la historia de la salud pública. Mexico: Siglo Veintiuno, 1990.

SILVA JÚNIOR, A. G.; MERHY, E. E.; CARVALHO, L. C. Refletindo sobre o ato de cuidar da saúde. In: PINHEIRO, R.; MATTOS, R. A. (Orgs.) Construção da integralidade: cotidiano, saberes e práticas em saúde. Rio de Janeiro: IMS/UERJ-Abrasco, 2003. p.113-28.

STEIN, E. Seis estudos sobre ser e tempo. Petrópolis: Vozes, 1988.

TEIXEIRA, R. R. Estudo sobre a técnica e a saúde. 2003. Tese (Doutorado) - Faculdade de Medicina, Universidade de São Paulo, São Paulo.


AYRES, J. R. C. M. Cuidado y reconstrucción de las prácticas de Salud, Interface Comunic., Saúde, Educ., v.8, n.14, p.73-92, set.2003-fev.2004.

Presenciamos recientemente la emergencia de una serie de nuevos discursos en el campo de la salud pública, mundial y nacionalmente, tales como la promoción de la salud, vigilancia de la salud, salud de la familia, reducción de vulnerabilidad, entre otros. No obstante, una efectiva consolidación de esas propuestas y su consecuente desarrollo parecen depender de transformaciones bastante radicales en nuestro modo de pensar y hacer salud, especialmente en sus presupuestos $y$ fundamentos filosóficos. Es en la condición de una desconstrucción teórica, con vistas a contribuir a la reconstrucción en curso en las prácticas de salud, que se quiere poner en debate la presente reflexión. En ese sentido, se examina el cuidado bajo tres perspectivas conceptuales: como categoría ontológica, como categoría genealógica y como categoría crítica. La hermenéutica realizada en la interfaz de esas tres perspectivas permite apuntar direcciones donde parece productivo un esfuerzo de reconstrucción de las prácticas de salud: un activo movimiento de profesionales y servicios de salud en el sentido de dedicarse activamente a la presencia del otro en el espacio asistencial, la optimización y diversificación de las formas y calidad de la interacción yo-otro en esos espacios y el enriquecimiento de los horizontes de conocimientos y prácticas en salud en una perspectiva decididamente interdisciplinar e intersectorial.

PALABRAS CLAVE: Promoción de la salud; práctica de salud pública. 


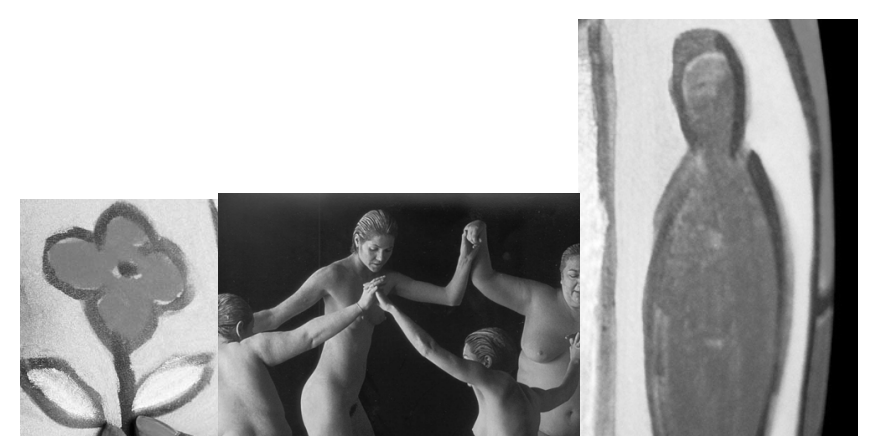

92 Interface - Comunic., Saúde, Educ., v.8, n.14, p.73-92, set.2003-fev.2004 